\title{
Supervisory Circuits in a Mixed Neutron and Gamma Radiation Environment
}

\author{
Y. Zong, F. J. Franco, A. H. Cachero and J. A. Agapito \\ Dep. Física Aplicada III, Facultad de CC. Físicas, \\ Universidad Complutense de Madrid, \\ 28040, Madrid, Spain \\ yzong@fis.ucm.es
}

\author{
A. C. Fernandes and J. G. Marques \\ Portuguese Research Reactor, \\ Instituto Tecnologico e Nuclear, Estrada Nacional 10, \\ Sacavém, Portugal \\ anafer@itn.mcies.pt
}

\author{
M. A. Rodríguez-Ruiz and J. Casas-Cubillos \\ CERN, Accelerator Technology Division, \\ Geneva 23, CH-1211, \\ Geneva, Switzerland \\ Juan.Casas-Cubillos@cern.ch
}

\begin{abstract}
This paper describes the evolution of different commercial microprocessor supervisory circuits under neutron and gamma radiation. After the irradiation, the tested devices showed some interesting changes: an increase of supply current and the period of watchdog timer. It was also observed that threshold voltage hysteresis and the shift of TTL trigger level appeared in some devices.
\end{abstract}

Keywords-COTS; supervisory circuits; TID

\section{INTRODUCTION}

Since FPGA (Field Programmable Gate Array) is the densest and most advanced programmable logic device, it enables a designer to implement large digital design in a device at any location. FPGAs will be present in the electronic instrumentation of the cryogenic system of the Large Hadron Collider (LHC) at CERN (European Organization for Nuclear Research). However, these devices might suffer unexpected stops, caused by single events, power failures, etc., so additional devices with a watchdog function are essential to be added into the system in order to avoid the sudden failures.

The special functions of microprocessor supervisory circuits make them suitable to be connected to the FPGA clock output, not only to detect sudden FPGA failures but to protect the whole system. In fact, if the clock signal does not appear for 1-2 s, they provide a reset signal to restart the FPGA. This signal will last until the FPGA clock signal is detected again.

However, the selection of the supervisory circuit must be carefully done since a neutron fluence of $5 \cdot 10^{13} \mathrm{n} \cdot \mathrm{cm}^{-2}$ and a total gamma dose of 1-3 kGy (Si) are expected for a 10 year activity period in the LHC cryogenic system. The energy spectrum of the radiation is similar to that of ${ }^{235} \mathrm{U}$ after

This work was supported by the cooperative agreement K746/LHC between CERN \& UCM, by the Spanish Research Agency CICYT (FPA200200912) and partially supported by Instituto Tecnológico e Nuclear of Portugal removing thermal neutrons. Therefore, commercial supervisory circuits must tolerate this level of radiation without significant degradation.

\section{DEVICES AND TeSt SET-UP}

Four samples of several CMOS models from different companies (ADM692, from Analog Devices; MAX690, MAX1232 \& MAX6304, from Maxim) were selected to be irradiated in a special neutron facility at the Portuguese Research Reactor [1], which was built in order to simulate the radiation environment expected in the LHC cryogenic system. An irradiation test performed for a week is equivalent to 10 years of LHC operation.

\section{A. Description of the tested supervisory circuits}

Although the complete datasheets of the tested supervisory circuits can be obtained from the companies [2][3], a brief description will be given here.
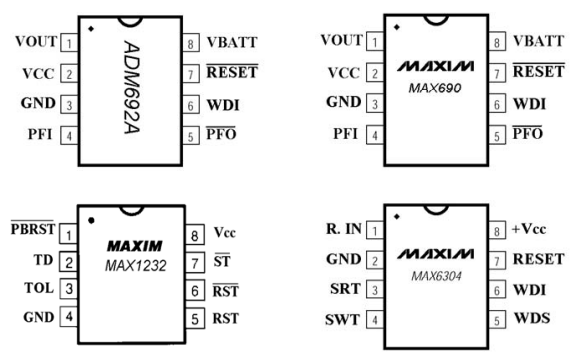

Figure 1. The pin layout of the tested supervisory circuits (ADM692 and MAX690 have the same pin configuration)

The tested supervisory circuits are all in DIP8 package (Fig. 1) and all of them provide the functions of up RESET, backup-battery switchover, watchdog timer, power failure warning and CMOS RAM writing protection. The watchdog function enables the RESET output voltage to become a periodic square wave signal under specific conditions. 
Differences among them are the value of the RESET threshold voltage, the threshold voltage for the detection of power failure interruption as well as the period and delay of the watchdog timer. Furthermore, the periods of the watchdog timer of ADM692 and MAX690 are set to $1.6 \mathrm{~s}$, while the other products of Maxim's have adjustable watchdog timer depending on the network connected to some special pins. Moreover, only MAX1232 does not require external components while the other supervisory circuits need some external resistors or capacitances to adjust their reset threshold voltage or the period of watchdog timer. Finally, samples of Analog Device are fabricated using an advanced epitaxial CMOS process combining low consumption and high reliability and $\overline{R E S E T}$ is guaranteed with $V_{C C}$ as low as $1 \mathrm{~V}$.

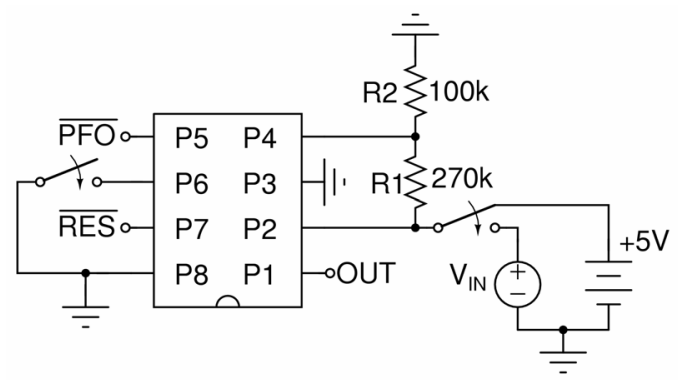

Figure 2: Test circuit for ADM692 and MAX690

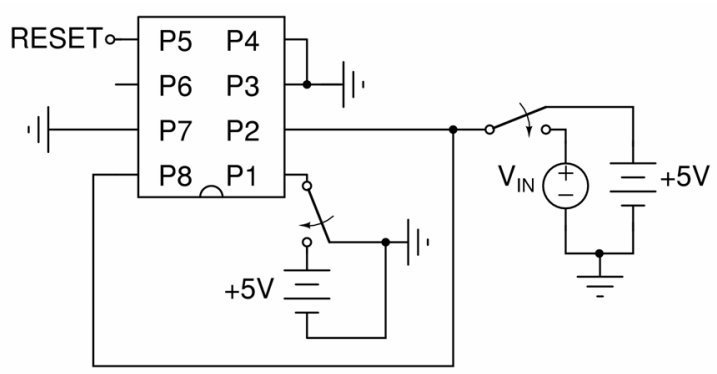

Figure 3: Test circuit for MAX1232

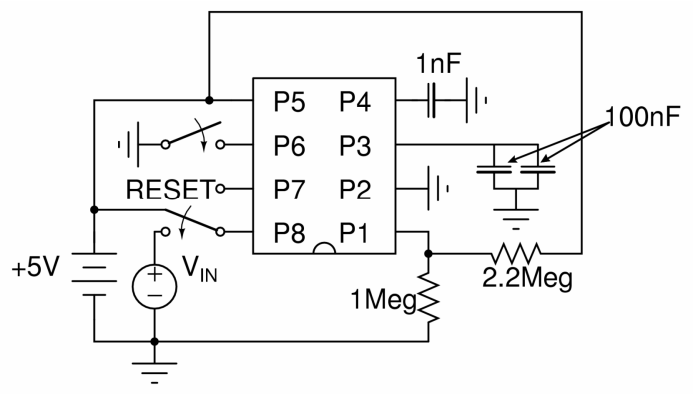

Figure 4: Test circuit for MAX6304

\section{B. $\quad$ Test procedures}

On-line test circuits are shown in Fig. 2-4. During most of the irradiation, the devices were biased by a $+5 \mathrm{~V}$ power supply but, during the characterization, this voltage source is replaced by another one, $V_{I N}$, which is variable and controlled by the measuring system. Thus, the relationship between the inputs $\left(+V_{C C}\right.$ or $\left.P F I\right)$ and the outputs $(O U T, \overline{P F O} \& \overline{R E S E T})$ were measured on-line doing an automatic DC sweep in $V_{I N}$ and storing the value of the output voltages.

The start and end values of the DC sweep were $3 \mathrm{~V}$ and $5.5 \mathrm{~V}$, with an increasing step of $50 \mathrm{mV}$. In the case of MAX690 \& ADM692, the PFI (pin4) was connected to a resistor network for the purpose of scaling the input voltage by a factor of 3.7. The pin $\overline{P F O}$ switches to zero when PFI is less than $1.3 \mathrm{~V}$. PFI voltage varies from 0.811 to $1.486 \mathrm{~V}$ when $+V_{C C}$ is swept from $3 \mathrm{~V}$ to $5.5 \mathrm{~V}$. The main characteristic parameters of each supervisory circuit before the irradiation are shown in Table I.

TABLE I: THE MAIN PARAMETERS OF THE TESTED SUPERVISORY CIRCUITS BEFORE IRRADIATION

\begin{tabular}{|c|c|c|c|c|}
\hline PARAMETERS & ADM692 & MAX690 & MAX1232 & MAX6304 \\
\hline $\begin{array}{c}\text { Watchdog timeout } \\
\text { period (s) }\end{array}$ & 1.6 & 1.6 & 1.2 & 1.87 \\
\hline $\begin{array}{c}\text { Input threshold voltage } \\
\text { for power fail warning (V) }\end{array}$ & 1.25 & 1.3 & 2.0 & 1.22 \\
\hline $\begin{array}{c}\text { Reset voltage } \\
\text { threshold (V) }\end{array}$ & 4.4 & 4.65 & 4.75 & 3.9 \\
\hline $\begin{array}{c}\text { Reset threshold } \\
\text { hysteresis (mV) }\end{array}$ & 40 & 20 & No & 20 \\
\hline
\end{tabular}

A set of mechanical relays, not affected by radiation, were placed on the test boards. Some of them had the purpose of isolating the device when they were not being characterized while others were used to connect some logic inputs to ground or to $+5 \mathrm{~V}$ in order to check the watchdog function.

Test printed circuit boards (PCBs) were connected to the measuring system, which consisted of a PC, an I-V source measure unit, an 8 1/2 digits multimeter and a switch system with 40 -channel multiplexer cards \& $4 \times 10$ matrix cards. The control program is performed by the object-oriented language Testpoint. During the irradiation, the PC system checked the main parameters of the devices every ten minutes and their values were stored in several files with date and time for a later study. Unfortunately, some parameters could not be measured during the irradiation (e.g., the width of the hysteresis cycle, the watchdog period, etc.) so they were eventually measured one month after the irradiation when the devices could be safely handled. Meanwhile, devices were unbiased and stored at room temperature.

\section{Radiation environment and radiation effects}

The supervisory circuits were exposed to radiation at a special facility of the Portuguese Research Reactor, which operated at nominal power of $1 \mathrm{MW}$. The tested circuits were packed in a box and placed in a hermetic cylindrical aluminum container before being put in the neutron facility. In the center of the cavity of the facility, values of total radiation dose provided in section I were achieved after 5 sessions of 12 hours each (on the whole, $60 \mathrm{~h}$ ). Neutron fluence values were measured with the ${ }^{58} \mathrm{Ni}$ detectors, which were placed at center of the boxes that contained every PCB. At the same time, the total ionizing dose was taken by the measuring system with an ionization chamber. Table II lists the values of radiation 
received by each sample as well as the dose rate and the ratio between the neutron fluence, $\Phi$, and TID.

TABLE II: NEUTRON AND IONIZING RADIATION RECEIVED BY THE CIRCUITS

\begin{tabular}{|c|c|c|c|c|}
\hline $\begin{array}{c}\boldsymbol{\Phi} \\
\mathrm{n} \cdot \mathrm{cm}^{-2}\end{array}$ & $\begin{array}{c}\text { FLUX } \\
\mathrm{n} \cdot \mathrm{cm}^{-2} \cdot \mathrm{s}^{-1}\end{array}$ & $\begin{array}{c}\text { TID } \\
\text { Gy }\end{array}$ & $\begin{array}{c}\text { DOSE RATE } \\
\text { Gy/h }\end{array}$ & $\begin{array}{c}\boldsymbol{\Phi} / \text { TID RATIO } \\
\mathrm{n} \cdot \mathrm{cm}^{-2} / \mathrm{Gy}\end{array}$ \\
\hline $9.51 \mathrm{E}+13$ & $4.40 \mathrm{E}+08$ & 1655 & 27.58 & $5.75 \mathrm{E}+10$ \\
\hline $7.18 \mathrm{E}+13$ & $3.32 \mathrm{E}+08$ & 1335 & 22.25 & $5.38 \mathrm{E}+10$ \\
\hline $5.43 \mathrm{E}+13$ & $2.51 \mathrm{E}+08$ & 1095 & 18.25 & $4.96 \mathrm{E}+10$ \\
\hline $3.97 \mathrm{E}+13$ & $1.84 \mathrm{E}+08$ & 900 & 15 & $4.41 \mathrm{E}+10$ \\
\hline
\end{tabular}

As it was previously mentioned, the energy spectrum of the neutron beam was similar to that of the ${ }^{235} \mathrm{U}$ decay after removing the component of thermal neutrons. According to the calculations performed in the Portuguese Research Reactor, the damage factor value is 1.28 . In other words, all the neutron fluence values shown in this paper, whether in graphs or in tables, can be expressed in the standard unit of $1 \mathrm{MeV}$-neutrons $/ \mathrm{cm}^{2}$ just multiplying them by 1.28 .

The neutron radiation produces defects in semiconductor materials that reduce the minority carrier lifetime, majority carrier density and mobility [4]. However, despite all these parameters being affected by radiation, it is evident that minority carrier lifetime is the most sensitive electronic property of silicon in the neutron environment. The degradation of minority carrier lifetime results in changes in semiconductor device properties such as the current gain of bipolar transistors, storage time, saturation voltage and sink current. Carrier removal is the next most important characteristic of displacement damage and causes a decrease in carrier mobility and an increase in resistivity.

On the contrary, gamma radiation causes the appearance of trapped positive charges inside the $\mathrm{SiO}_{2}$. Both kinds of defects (trapped holes or interface states) accumulate to affect the behavior of the semiconductor devices. In CMOS technologies, the consequences include the shift of the threshold voltage of transistors, the decrease of the surface mobility and, stemming from it, the decrease of the transconductance and, finally, the appearance of leakage currents.

\section{RESULTS}

As expected, all the devices suffered strong degradation of their electrical characteristics. In the summary, the damage was much more remarkable in the devices from Maxim than that in those of Analog Devices. Now, the main parameters will be enumerated and their corresponding evolutions depicted.

1) Supply Currents: All the devices are built in CMOS technology so it is interesting to start this study by examining the evolution of supply currents, a parameter that was measured every few minutes during the irradiation.

In most devices, this parameter increases up to values far away from the initial ones. E. g., the supply current of a sample of MAX6304 that received 1200 Gy is about $15 \mathrm{~mA}$ at the end of the irradiation (fig. 5). This evolution is easily explained by means of the appearance of leakage currents, already described in different irradiated CMOS devices [5].

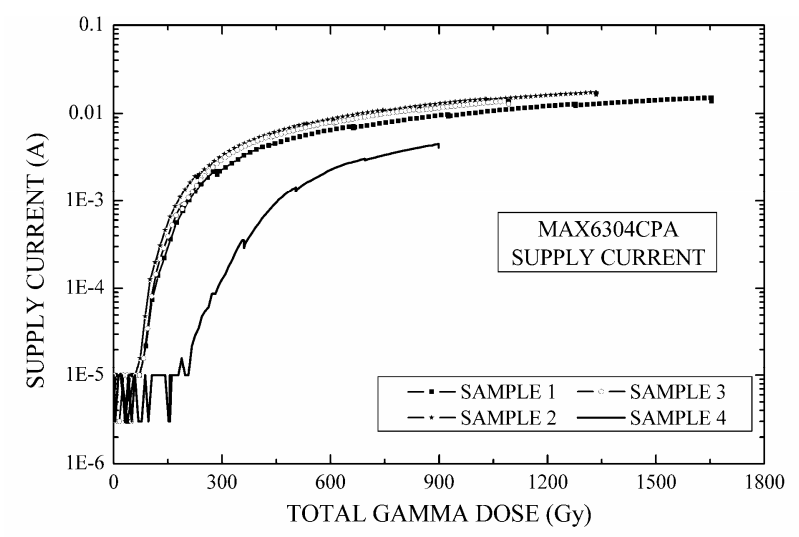

Figure 5: Evolution of the supply current as a function of total gamma dose for MAX6304

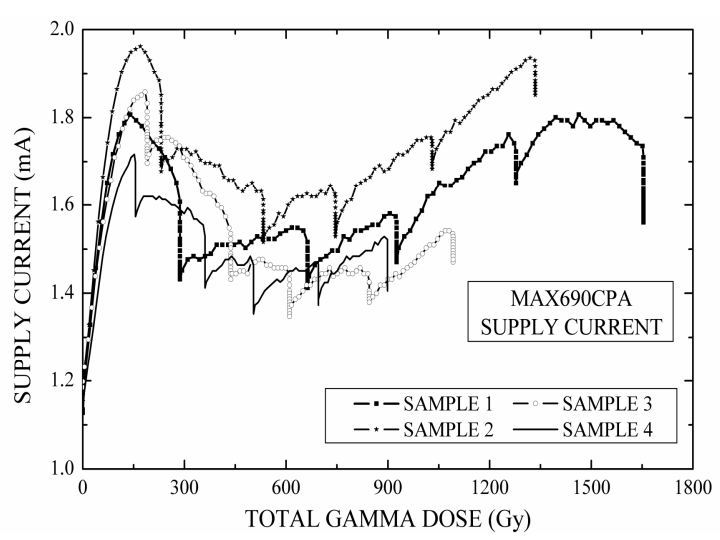

Figure 6: Evolution of the supply current as a function of total gamma dose for MAX690

Fig. 6 showed the evolution of the supply current for MAX690. Its value quickly soars until reaching a peak around 150 Gy. Later, the supply current shows a decrease, a stage that ends when a new minimum is reached at about 500-700 Gy. Next, the current value underwent a final steady growth. In any case, the value is always lower than $2.0 \mathrm{~mA}$. This kind of evolution, which consists of a sudden increase in supply current, followed by a drop and then a much slower growth, has been found by other authors in CMOS devices irradiated under the same conditions [6].

The evolution of the supply current for ADM692, summarized in fig. 7, is quite similar to that of the former device. The supply current is constant up to 100-120 Gy. Then, it started growing. Three of the four samples reached the highest value $(5 \mathrm{~mA})$ at about $750 \mathrm{~Gy}$. Then, the higher the total gamma dose, the lower the current. The fourth sample seems more tolerant than the other ones, maybe due to either a lower dose rate or differences during batch manufacturing.

Unlike previous devices, the behavior of the MAX1232 samples does not follow the usual pattern of behavior (fig. 8). The supply current decreases instead of growing. This odd behavior can be explained as a consequence of the 
displacement damage caused by neutron irradiation, as it is explained in section IV.

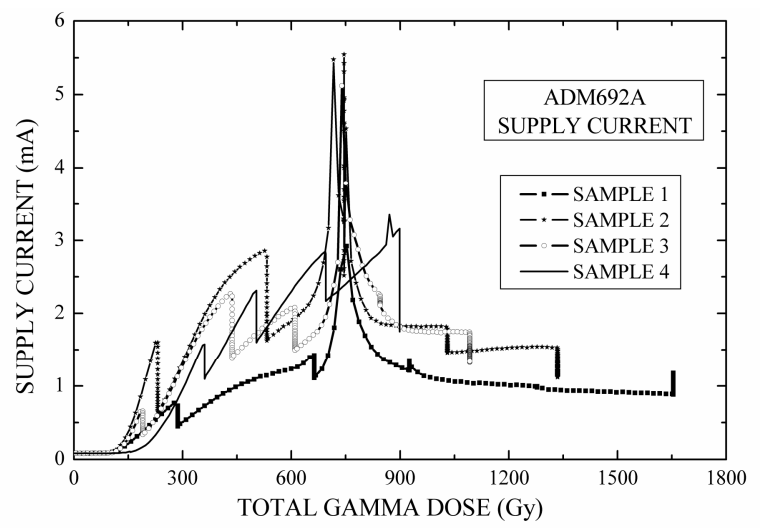

Figure 7: Evolution of the supply current as a function of total gamma dose for ADM692

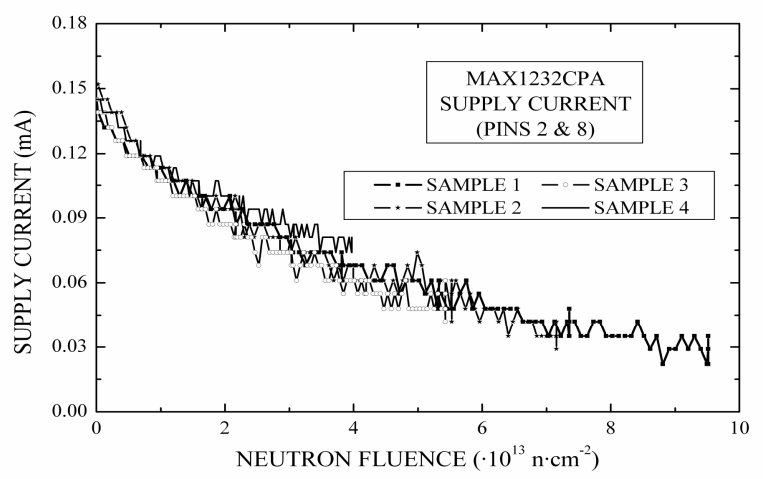

Figure 8: The evolution of the supply current as a function of the neutron fluence for MAX1232

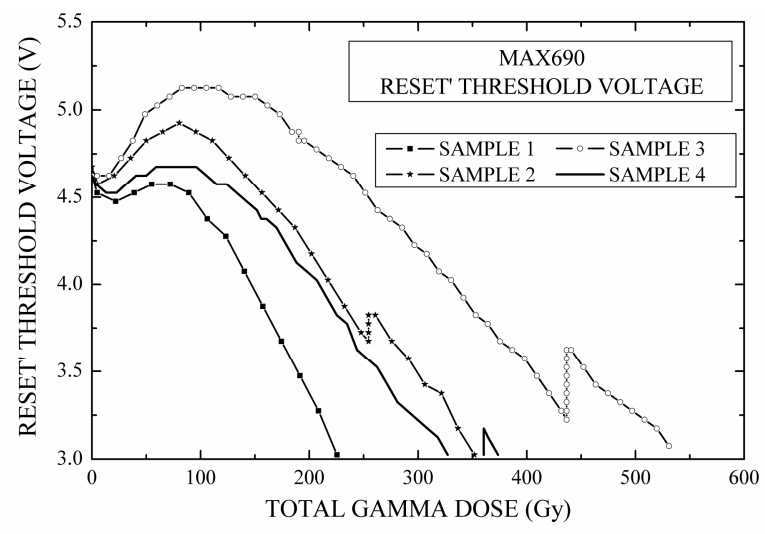

Figure 9: Evolution of $\overline{R E S E T}$ threshold voltage in MAX690

2) Watchdog Function: The evolution of this function is very interesting. The period of the watchdog signal only could be measured before and after the irradiation. However, the online measuring system managed to detect the presence of digital pulses so that the persistence or disappearance of the watchdog function could be tracked during the irradiation.
The watchdog feature quickly disappears in MAX6304 \& MAX1232 sample but it remains in the other two devices. In three samples of ADM692, the watchdog function stopped working when the total gamma dose was about 750 Gy. Only the fourth one, which received a lower total ionizing dose, worked until the end of the irradiation. Fortunately, when these samples were checked after the isotope deactivation, we learnt that they had recovered the ability to work. In the case of MAX690, only the most irradiated device would not work after the irradiation.

Analyzing the results, a new and unknown phenomenon has come out: the shift of the watchdog signal period. The watchdog output signal is a square wave with different duty cycle values depending on the model. At the beginning, the period of the signal in ADM692 was about $1.6 \mathrm{~s}$ but, as the irradiation is carried out, this period increases, although, in the most irradiated samples, lower values of period were measured (Table III). Another significant characteristic is that the duty cycle has been hardly affected. However, this device is not the most appropriate to study this phenomenon. In fact, MAX690 showed spectacular increases in all the samples. E.g., the period of a sample of MAX690 suffered an increase from $1.6 \mathrm{~s}$ up to $49.2 \mathrm{~s}$ after receiving $7.18 \cdot 10^{13} \mathrm{n} \cdot \mathrm{cm}^{-2} \& 1335$ Gy (Si). The rest of experimental data are shown in Table IV.

TABLE III: CHARACTERISTICS OF THE $\overline{R E S E T}$ OUTPUT IN ADM692

\begin{tabular}{|c|c|c|c|c|}
\hline SAMPLE & $\begin{array}{c}\text { TID } \\
\text { Gy }\end{array}$ & $\begin{array}{c}\boldsymbol{\Phi} \\
\mathrm{n} \cdot \mathrm{cm}^{-2}\end{array}$ & $\begin{array}{c}\text { PERIOD } \\
\mathrm{s}\end{array}$ & DUTY CYCLE \\
\hline 1 & 1665 & $9.51 \cdot 10^{13}$ & 1.567 & $88.70 \%$ \\
\hline 2 & 1335 & $7.18 \cdot 10^{13}$ & 1.483 & $88.20 \%$ \\
\hline 3 & 1095 & $5.43 \cdot 10^{13}$ & 1.481 & $87.71 \%$ \\
\hline 4 & 900 & $3.97 \cdot 10^{13}$ & 1.706 & $87.46 \%$ \\
\hline INITIAL & 0 & 0 & 1.6 & $85.74 \%$ \\
\hline
\end{tabular}

TABLE IV: CHARACTERISTICS OF THE $\overline{R E S E T}$ OUTPUT IN MAX690

\begin{tabular}{|c|c|c|c|c|}
\hline SAMPLE & $\begin{array}{c}\text { TID } \\
\text { Gy }\end{array}$ & $\begin{array}{c}\boldsymbol{\Phi} \\
\mathrm{n} \cdot \mathrm{cm}^{-2}\end{array}$ & $\begin{array}{c}\text { PERIOD } \\
\mathrm{s}\end{array}$ & DUTY CYCLE \\
\hline 2 & 1335 & $7.18 \cdot 10^{13}$ & 49.2 & $96.91 \%$ \\
\hline 3 & 1095 & $5.43 \cdot 10^{13}$ & 29.3 & $96.75 \%$ \\
\hline 4 & 900 & $3.97 \cdot 10^{13}$ & 12.2 & $96.76 \%$ \\
\hline INITIAL & 0 & 0 & 1.6 & $96.87 \%$ \\
\hline
\end{tabular}

3) Additional Features: Although the main goal of the radiation tests on these devices is to find out the behaviour of the watchdog function, the devices have other interesting features that were investigated. For instance, some devices have an additional digital output (PFO) that switches from $H I G H$ to $L O W$ if the value of the power supply becomes lower than a safety threshold level. Thus, the digital system is warned against a possible power failure so the data can be saved. The radiation test showed that the trigger value changes during the irradiation. Moreover, a similar behaviour was found in other parameters and, in some devices, it leads to the paradox that the trigger level is outside the range of the usual $0-5 \mathrm{~V}$ TTL levels. This was observed in the evolution of the 
$\overline{R E S E T}$ threshold voltage of MAX690 during the irradiation (fig. 9).

TABLE V: $\overline{R E S E T}$ THRESHOLD VOLTAGE FOR ADM692

\begin{tabular}{|c|c|c|c|c|}
\hline $\begin{array}{c}\text { TID } \\
(\mathrm{Gy})\end{array}$ & $\begin{array}{c}\boldsymbol{\Phi} \\
\left(\mathrm{n} \cdot \mathrm{cm}^{-2}\right)\end{array}$ & $\begin{array}{c}\text { RESET TH. } \\
\text { DOWN }(\mathrm{V})\end{array}$ & $\begin{array}{c}\text { RESET TH. } \\
\mathbf{U P}(\mathrm{V})\end{array}$ & $\begin{array}{c}\text { HYSTERESIS } \\
(\mathrm{mV})\end{array}$ \\
\hline 1665 & $9.51 \cdot 10^{13}$ & 4.73 & 4.76 & 30 \\
\hline 1335 & $7.18 \cdot 10^{13}$ & 4.96 & 5.24 & 280 \\
\hline 1095 & $5.43 \cdot 10^{13}$ & 4.69 & 4.95 & 260 \\
\hline 900 & $3.97 \cdot 10^{13}$ & 4.45 & 4.72 & 270 \\
\hline
\end{tabular}

Furthermore, in the upward and downward $\overline{R E S E T}$ threshold voltage of ADM692, hysteresis phenomena were observed before the irradiation and the irradiation brought about an increase of the hysteresis cycle width (Table V). In this table, RESET THRESHOLD DOWN is related to a decreasing value of the power supply. On the contrary, the $\overline{R E S E T}$ THRESHOLD UP value is defined in the opposite situation. Obviously, both values are not equal due to hysteresis phenomena and it is interesting to note that, in some devices, one of the threshold values is in the range of TTL levels while the other value is not (e.g., the sample of ADM692 that received 1335 Gy \& $\left.7.18 \cdot 10^{13} \mathrm{n} \cdot \mathrm{cm}^{-2}\right)$.

TABLE VI: HIGHEST CURRENT THAT ADM692 OUTPUTS CAN SUPPLY AFTER THE IRRADIATION

\begin{tabular}{|c|c|c|c|c|c|}
\hline SAMPLE & $\begin{array}{c}\boldsymbol{\Phi} \\
\mathrm{n} \cdot \mathrm{cm}^{-2}\end{array}$ & $\begin{array}{c}\text { TID } \\
\text { Gy }\end{array}$ & $\begin{array}{c}\text { OUT } \\
\mathrm{A}\end{array}$ & $\begin{array}{c}\overline{R E S E T} \\
\mathrm{~mA}\end{array}$ & $\begin{array}{c}\overline{P F O} \\
\mathrm{~mA}\end{array}$ \\
\hline 1 & $9.51 \cdot 10^{13}$ & 1655 & $>1$ & 4.8 & 4.8 \\
\hline 2 & $7.18 \cdot 10^{13}$ & 1335 & $>1$ & 4.7 & 4.7 \\
\hline 3 & $5.43 \cdot 10^{13}$ & 1095 & $>1$ & 4.9 & 5.0 \\
\hline 4 & $3.97 \cdot 10^{13}$ & 900 & $>1$ & 5.4 & 5.4 \\
\hline INITIAL & 0 & 0 & $>1$ & 5.5 & 5.5 \\
\hline
\end{tabular}

TABLE VII: HIGHEST CURRENT THAT MAX690 OUTPUTS CAN SUPPLY AFTER THE IRRADIATION

\begin{tabular}{|c|c|c|c|c|c|}
\hline SAMPLE & $\begin{array}{c}\boldsymbol{\Phi} \\
\mathrm{n} \cdot \mathrm{cm}^{-2}\end{array}$ & $\begin{array}{c}\text { TID } \\
\text { Gy }\end{array}$ & $\begin{array}{c}\text { OUT } \\
\mathrm{mA}\end{array}$ & $\begin{array}{c}\overline{R E S E T} \\
\mu \mathrm{A}\end{array}$ & $\begin{array}{c}\overline{P F O} \\
\mu \mathrm{A}\end{array}$ \\
\hline 1 & $9.51 \cdot 10^{13}$ & 1655 & 2.29 & 0 & 0 \\
\hline 2 & $7.18 \cdot 10^{13}$ & 1335 & 2.30 & 0.1 & 0.1 \\
\hline 3 & $5.43 \cdot 10^{13}$ & 1095 & 8.0 & 0.1 & 0.1 \\
\hline 4 & $3.97 \cdot 10^{13}$ & 900 & 21 & 3.5 & 3.5 \\
\hline INITIAL & 0 & 0 & $>1 \mathrm{~A}$ & 8 & 8 \\
\hline
\end{tabular}

Finally, the MAX690 \& ADM692 have a special output with the purpose of notifying the system in case the main power supply should fail. Both kinds of devices have three outputs: OUT, $\overline{R E S E T} \& \overline{P F O}$, whose functions were described in previous sections. Table VI shows the highest current that the outputs can supply in proportion to the total radiation dose. In the case of the ADM692, the currents have hardly changed. Indeed, the OUT pin can supply more than 1A even after receiving a total radiation dose of $1665 \mathrm{~Gy}(\mathrm{Si}) \&$
$9.51 \cdot 10^{13} \mathrm{n} \cdot \mathrm{cm}^{-2}$. The other outputs are not affected until going beyond 900 Gy but the reduction is not too large. On the contrary, the output current is strongly affected in MAX690 samples (Table VII). This device can provide more than $1 \mathrm{~A}$ before the irradiation but, after receiving $7.18 \cdot 10^{13} \mathrm{n} \cdot \mathrm{cm}^{-2} \&$ $1335 \mathrm{~Gy}(\mathrm{Si})$, the output only provides $2.3 \mathrm{~mA}$. Furthermore, the highest current that $\overline{R E S E T} \& \overline{P F O}$ can supply is $8 \mu \mathrm{A}$ before the irradiation and $3.5 \mu \mathrm{A}$ after it.

\section{DISCUSSION}

The set of data reported in the previous section allows a full understanding of the radiation effects on supervisory circuits. However, there are so far unknown phenomena that should be explained or, at least, the possible reasons of those behaviors postulated.

Firstly, the decrease of the supply current of MAX1232 is a phenomenon that contradicts the anticipated increasing power consumption in CMOS devices. We consider that it is associated with the effects of displacement damage. One of the main effects of this kind of damage is resistivity growth and, perhaps, the internal resistors of the device have increased in such a way that the current provided by the power supply is to decrease. Besides, the decrease of the supply current is also a hint of the absence of parasitic leakage currents beneath the epitaxial oxide.

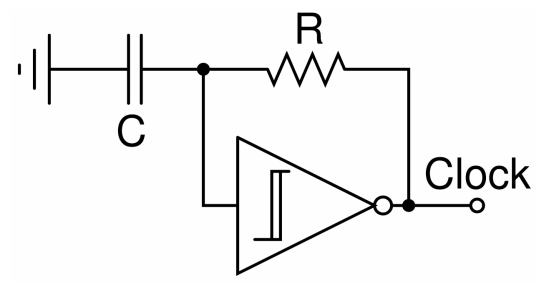

Figure 10: A typical Schmitt clock generator

Another interesting point is the unexpected increase of the watchdog function period. In order to explain this phenomenon, we can make use of a simple Schmitt clock, like that of fig. 10. In this structure, the signal period is set by means of an external capacitor. This clock signal generator, or at least advanced versions of this simple network, is widely used when designing digital devices. After analyzing this network, we can easily conclude that the output is a square wave with a period proportional to $R \cdot C$ and with a duty cycle obtained from the values of $V_{C C}$ and the trigger voltage values of the CMOS Schmitt inverter, $V_{U P} \& V_{D O W N}$.

During the radiation, the value of capacitance hardly changes, as some papers have stated [7], while the silicon resistivity increases [4]. Thus, if the internal resistor is a silicon type, which is the usual technology to obtain resistors of several tens of $\mathrm{k} \Omega$, the resistance value must increase and, in consequence, increases the period of the signal output.

The behavior of the irradiated CMOS Schmitt trigger may also depend on the fact that the duty cycle depends on other factors different from the RC product. Although the actual structure of the supervisory circuit clocks is unknown, these factors may be a clue to why the value of the duty cycle is scarcely affected by radiation damage. 
CMOS supervisory circuits also showed a shift in the values of threshold voltages, like those of RESET, PFI, etc. Similar changes have been found by the authors in other CMOS devices [8] and also reported in other works [9].

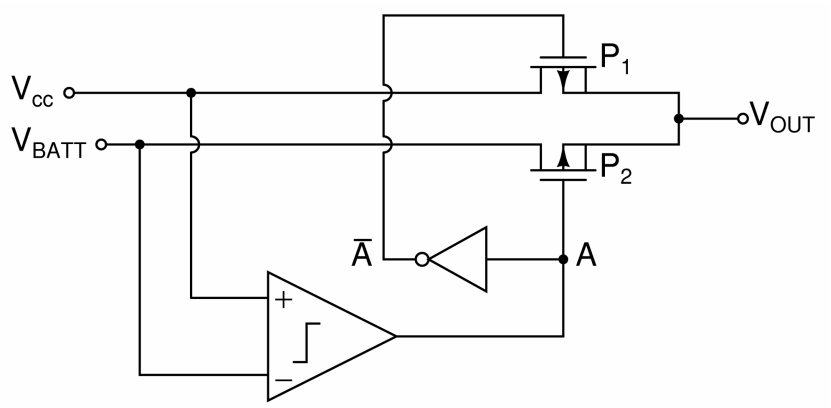

Figure 11: Output topology of MAX690 and ADM692

In addition, there are several possible causes which lead the output current of the MAX690 to decrease in proportion to the irradiation. According to the output topology (Fig. 11), there are two PMOS transistors in the output channel of the MAX690. A comparator and a CMOS inverter are devoted to select the power supply connected to the device output. This link is made by means of a couple of PMOS transistors whose drain current can be described as follows:

$$
I_{D S, P}=\left\{\begin{array}{l}
\beta \cdot\left[2 \cdot\left(V_{S G}+V_{T H P}\right) \cdot V_{S D}-V_{S D}^{2}\right] \cdot\left(1+\lambda \cdot V_{D S}\right) \leftrightarrow \text { If } \mathrm{V}_{\mathrm{SD}} \leq \mathrm{V}_{\mathrm{SG}}+\mathrm{V}_{\mathrm{THP}} \\
\beta \cdot\left(V_{S G}+V_{T H P}\right)^{2} \cdot\left(1+\lambda \cdot V_{S D}\right) \leftrightarrow I f \mathrm{~V}_{\mathrm{SD}} \geq \mathrm{V}_{\mathrm{SG}}+\mathrm{V}_{\mathrm{THP}}
\end{array}\right.
$$

The situation where the device is supplying the maximum output current is when the output is grounded. Therefore, the ON transistor is in saturation mode since $V_{S G}=+V_{C C}=V_{S D}$ so $I_{M A X}=\beta\left(V_{C C}+V_{T H, P}\right)^{2}$. It is well known that the values of the transconductances $\beta$ decrease in irradiated transistors because of the diminution of the surface mobility, associated with TID as well as displacement damage [6]. Moreover, the threshold voltage of the PMOS transistor, which is always negative, rises during the irradiation. Hence, the drain current diminishes. A third factor that can also explain the reduction of the output current is related to the increase of the parasitic resistor present in all the field effect transistors. These resistors are mainly made up of silicon and are found between the metallizations and the MOSFET channel. Due to their semiconductor nature, their values are expected to increase and, in consequence, the current flowing between the power supplies and the output is limited. On all accounts, the above facts result in the output current of the MAX690 falling.
Finally, the output topology of $\overline{R E S E T}$ and $\overline{P F O}$ in the MAX690 is similar to a CMOS inverter which consists of a coupled pair of PMOS and NMOS transistors. It is obvious that the cause referred to previously can also be used to explain the decrease of the current of $\overline{R E S E T}$ and $\overline{P F O}$ in the MAX690.

\section{CONCLUSION}

Comparing with other tested devices, the ADM692 is the most tolerant one to the radiation. Moreover, these tests showed some interesting and relatively unknown phenomena.

First, the supply current decreases in the MAX1232. It is attributed to the displacement damage caused by neutron irradiation. Second, only the ADM692 and MAX690 maintain the watchdog function. At the same time, the MAX690 not only has an increase in the period width, but also a shift in the trigger level of the $\overline{R E S E T}$ threshold voltage. In addition, after the radiation the hysteresis cycle width increases in the ADM692.

In any case, these phenomena can be associated with the radiation effects on their internal basic CMOS devices.

\section{REFERENCES}

[1] P. Horowitz, W. Hill, "The Arts of Electronics", 2nd Edition, Cambridge University Press 1990.

[2] Homepage of Analog Devices, http://www.analog.com

[3] Homepage of Maxim, http://www.maxim-ic.com

[4] G. Messenger and A. S. Ash, "The Effects of Radiation on Electronic Systems", New York, Van Nostrand Reinhold, Second Edition, 1992

[5] S. Kerns et alt. "The Design of Radiation-Hardened ICs for Space: A Compendium of Approaches", Proceeding of the IEEE, vol. 76, no. 11, pp. 1470-1509, November 1988 .

[6] J. A. Agapito, J. Casas-Cubillos, F. J. Franco, B. Palan and M. A. Rodriguez-Ruiz, "Rad-Tol Field Electronics for the LHC Cryogenic System", Proceedings of the $7^{\text {th }}$ European Conferences on Radiation Effects on Component and Systems, pp. 653-657, Noordwijk, The Netherlands, September 2003.

[7] J. R. Srour and J. M. McGarrity "Radiation Effects on Microelectronics in Space", Proceeding of the IEEE, vol. 76, no. 11, pp. 1443-1469, November 1988.

[8] F. J. Franco, Y. Zong, J. A. Agapito, J. Casas-Cubillos and M. A. Rodriguez-Ruiz, "Evolution of Lowest Supply Voltage and Hysteresis Phenomena in Irradiated Analog CMOS Switches", IEEE Radiation Effects Data Workshop, July 2004, pp. 91-95.

[9] D. Larsen, P. Welling and W. Tsacoyeanes, "The Effects of Ionizing Radiation on the Honeywell HTMOS High-Temperature Linear CMOS Tecnology", IEEE Radiation Effects Data Workshop, July 1996, pp. 5561. 